\title{
Networked by design: Can policy requirements influence organisations' networking behaviour?
}

\author{
Federica Rossi ${ }^{\mathrm{a}, *}$, Annalisa Caloffi ${ }^{\mathrm{b}}$, Margherita Russo $^{\mathrm{c}}$ \\ a Department of Management, Birkbeck, University of London, Malet Street, Bloomsbury, London WC1E 7HX, UK \\ b Department of Economics and Business, University of Padua, Italy, via del Santo 33, Padova 35123, Italy \\ c Department of Economics, University of Modena and Reggio Emilia, viale Berengario 51, 41121 Modena, Italy
}

\section{A R T I C L E I N F O}

\section{Article history:}

Received 17 December 2014

Received in revised form 6 January 2016

Accepted 11 January 2016

Available online 1 February 2016

\section{Keywords:}

Innovation networks

Innovation policy

Policy requirements

Networking behaviour

Behavioural effects of policy

\begin{abstract}
A B S T R A C T
An important, but under-researched, question in relation to policies funding networks of innovators is: what kind of innovation networks should be supported, if the policy objective is not just to sponsor successful innovation projects, but also to encourage the participants to form networks with desirable characteristics? Focusing on a set of policy programmes implemented by the regional government of Tuscany, in Italy, between 2002 and 2008, aimed at funding networks of collaborating organisations, we investigate whether the imposition of requirements on the composition of the networks that would be eligible for funding - in particular, the demand that networks should comply with minimum size and heterogeneity thresholds - influenced the participants' networking behaviour in the context of successive policy interventions. Our results show that these requirements immediately affected the size and composition of the project networks that applied for funding, although not always in the intended direction. However, these effects did not extend to the successive periods, when those requirements were no longer in force. This suggests that the imposition of policy requirements, per se, is unlikely to induce persistent changes in organizations' networking behaviour. Other approaches such as implementing outreach actions in order to encourage new organisations to participate in existing innovation networks and to form new ones, and additional measures designed to foster learning opportunities for the participants, might be more effective tools to influence the networking behaviour of participating organisations.
\end{abstract}

(c) 2016 Elsevier Inc. All rights reserved.

\section{Introduction}

Alongside traditional research and development ( $R \& D$ ) policy interventions targeted at individual firms, policymakers are increasingly supporting the formation of innovation networks (such as R\&D consortia, networks of excellence, university-industry partnerships) among firms and other types of organisations. Particularly since the early 2000s, numerous policy interventions of this kind have been implemented at national and regional levels (Hagedoorn et al., 2000; Branstetter and Sakakibara, 2002; Caloghirou et al., 2004; Cunningham and Ramlogan, 2012; Crespi and Quatraro, 2013). At supra-national level, the EU Framework Programmes (FP) have provided funding to networks of cooperating organisations for almost three decades (Breschi and Malerba, 2009; Tindemans, 2009; Biggiero and Angelini, 2014).

The stated objectives of policies directed at innovation networks are usually to support joint R\&D, technology transfer activities or even, sometimes, networking per se, with a view to create a critical mass of experts or users in a certain discipline or technological area - as in the networks of excellence funded in the EU FPs 6 and 7 (Musiolik et al.,

\footnotetext{
* Corresponding author.

E-mail addresses: f.rossi@bbk.ac.uk (F. Rossi), annalisa.caloffi@unipd.it (A. Caloffi), margherita.russo@unimore.it (M. Russo).
}

2012). These policy interventions also allow participating organisations to gain experience in networking with external partners and in collaborating with them on a specific activity, which may improve their ability to engage in further innovation networks. While such behavioural effects are not generally considered the main objectives of these policies, they could constitute important outcomes, since they have the potential to generate long-lasting beneficial changes in the participants' competences and abilities (Clarysse et al., 2009; Duso et al., 2010).

The interest in the behavioural effects of policy interventions in support of innovation networks fits with the recent debate on 'behavioural additionality'. This concept was introduced by Buisseret et al. (1995) to capture the effect of a policy intervention on an organisation's way of undertaking $\mathrm{R} \& \mathrm{D}$, as opposed to the established concept of input additionality, which simply captured a policy's effect on the amount of $R \& D$ that an organisation engaged in. Over time, the concept has been expanded and refined, for example by Georghiou (1998) who suggested that these changes should be permanent in character and should allow for more efficient innovation performance (see Gök and Edler (2012), for a review). Within the broad realm of behavioural additionality, more specific concepts have also been introduced to capture particular kinds of behavioural changes induced by policy interventions, such as 'network additionality', intended as the ability of public funding instruments to increase networking and co-operation to a greater extent than 
would be present without such funding (Hyvarinen and Rautiainen, 2007), and 'cognitive capacity additionality' to capture the increase in an organisation's capabilities to engage in successful innovation (Bach and Matt, 2002, 2005).

While there has been some recent interest in the behavioural effects of policies in support of innovation networks (Fier et al., 2006; Chávez, 2011; Antonioli et al., 2014; Caloffi et al., 2015) the field is still relatively new. In particular, an important question for policy design is what kind of networks should be supported, if the objective of the policy is not just to fund successful innovation projects, but also to influence the participants' networking behaviour, enabling them to form networks with desirable features.

Many of the policy interventions that we observe in practice require the participants to comply with a number of relational features that are deemed to be conducive to successful collaborative innovation. For instance, policies funding networks of organizations tasked with realizing specific innovation projects often require each network to include a minimum number of SMEs and universities. However, the implications in terms of policy design may not be straightforward. In fact, imposing specific requirements on networks 'by design' may be counterproductive, encouraging participants to comply with rules that may not meet their specific needs and, ultimately, may decrease their opportunities for learning and networking.

In this study we investigate whether, by imposing requirements on the design of innovation networks, a policy intervention can affect the networking behaviour of participating organisations. In particular, we explore whether policy requirements induce organisations to set up networks with desirable features not only in order to apply to programmes where these requirements are present, but also in the context of subsequent programmes, where the requirements are removed.

Our empirical analysis builds upon a rich original dataset of all the organisations participating in a set of regional policy interventions implemented in the Italian region of Tuscany between 2002 and 2008. These interventions competitively allocated funding for the realisation of innovative projects carried out by networks of organisations: each project proposal had to be submitted by a purposefully created (and legally binding) consortium of organisations based in the region. ${ }^{1}$ Initially, some of these interventions imposed certain compulsory requirements on the composition of the networks that would be eligible for funding (specifically, on the number and types of organisations that they should include), while other interventions launched at a later stage did not impose any requirements, thereby allowing the participants to structure their networks freely.

As we explain in greater detail in the next sections, our data allow us to compare the behaviour of organisations involved in policy programmes where the requirements were present with the behaviour of the same organisations in programmes that did not include any requirements. In this way, we can observe if the organisations participating in the programmes adjusted their behaviour in line with the policymakers' designed requirements, even when such requirements were no longer mandatory. Our data do not allow us to determine whether the participants' behaviour has changed outside of the policy context, for example we cannot say whether they interact with more or different organisations in other settings. Because of the lack of information on the organisations' overall networking behaviour post-policy, and because of the lack of an external control group, the present analysis cannot estimate the 'behavioural additionality' effects of the policy

\footnotetext{
${ }^{1}$ Innovation networks set up in order to benefit from public funding are usually called 'consortia' in policy documents. In the rest of this paper, we use the term 'consortium' to refer to the legal entity set up in order to apply for funding, but we prefer the more general term 'innovation network' when discussing the networking behaviour of the organisations involved in the set up of these consortia. This is because the theoretical arguments about the desirability of certain network characteristics are mainly drawn from the organisational literature on innovation networks, and because our findings can be of relevance to any scenario in which private or public funders are considering the imposition of requirements in the formation of networks of collaborating organisations.
}

programme. However, the analysis captures some behavioural changes that have been induced by the policy, since it captures to what extent the participants have changed their networking behaviour when setting up subsequent consortia in order to benefit from public funding.

The paper is structured as follows. In the next section, we discuss the rationale underpinning the imposition of policy requirements in the formation of project consortia, and their possible results. In Section 3, we describe in some detail the policy programmes that are the focus of our analysis. In Section 4, we present our methodology. In Section 5 we present our empirical results, which we discuss in Section 6 . Section 7 concludes.

\section{Policy requirements and networking behaviour}

When designing policies supporting innovation networks, policymakers may impose different types of requirements depending on their objectives. Policymakers may wish to encourage technology transfer, and therefore choose to fund university-industry relationships. They may wish to strengthen the capability for applied research in a certain field, and therefore fund large-scale R\&D projects with a preponderance of universities and research institutions. Or they may wish to encourage SMEs to collaborate in R\&D and adopt innovations. In this case - as in the programmes analysed in the present study - policymakers can impose various requirements on network composition. For example, they can require networks to include SMEs, which represent the target of their intervention. They can demand the involvement of universities, research centres, or intermediaries like technology transfer specialists that provide innovation support services. The underlying assumption is that policies are needed to stimulate interactions that would not occur spontaneously, but whose presence would be desirable (Carlsson and Jacobsson, 1997). Given SMEs' reluctance to embark on collaborative relationships (Bougrain and Haudeville, 2002; Narula, 2004; Muscio, 2007), policymakers could require networks to include a minimum number of participants, with the aim of broadening their connections. In order to encourage firms' openness to external sources of knowledge and to avoid knowledge lock-ins, policymakers may require the involvement of extra-regional or international participants (Dettman et al., 2012; Antonioli et al., 2014). Table 1 summarizes these possible requirements and related policy rationales, building on arguments presented by the literature on innovation networks, and presents, by way of illustration, examples of policies where such requirements have been imposed.

The immediate effect of these requirements is to encourage organisations wishing to benefit from public funds to set up networks that meet such requirements. However, policymakers often have more complex goals in mind, for example they might wish to encourage organisations to persistently adopt collaborative behaviours that are potentially conductive to innovation. ${ }^{2}$ This approach is consistent with what the innovation literature refers to as 'behavioural additionality', a concept that captures the extent to which participation in a policy intervention results in a persistent change in the behaviour of the organisations that have benefited from public funds - in what they are doing and in how they are doing it (Buisseret et al., 1995; Clarysse et al., 2009). In the context of policies supporting innovation networks, an important behavioural result would be to encourage the participants to build networks that are potentially conductive to innovation, not only in the context of the programme where these behaviours are explicitly required, but also beyond.

In what follows we consider two types of policy requirements for innovation networks: the imposition of a minimum number of participants (henceforth referred to as 'minimum network size' requirement)

\footnotetext{
2 Such more complex goals underpin, for example, several European Commission programmes which influence national and regional policies in Europe (see, for instance, the FP7-ICT and CIP ICT-PSP programmes, the European Innovation Partnerships, and Horizon 2020).
} 
Table 1

Types of policy requirements that can be imposed on the formation of innovation networks, and related policy rationales.

\begin{tabular}{|c|c|c|}
\hline Policy requirement & Policy rationale & $\begin{array}{l}\text { Policy including such } \\
\text { requirement }\end{array}$ \\
\hline $\begin{array}{l}\text { Minimum number of } \\
\text { organisations to be } \\
\text { included in the } \\
\text { network }\end{array}$ & $\begin{array}{l}\text { A critical mass of } \\
\text { resources, competencies } \\
\text { and relationships is } \\
\text { needed in order to carry } \\
\text { out an innovative project. }\end{array}$ & $\begin{array}{l}\text { Japanese policies funding } \\
\text { R\&D consortia } \\
\text { (1980-1992); } \\
\text { (Sakakibara (1997)) }\end{array}$ \\
\hline $\begin{array}{l}\text { Organisations of a } \\
\text { particular nature to be } \\
\text { included in the } \\
\text { network }\end{array}$ & $\begin{array}{l}\text { Different competencies } \\
\text { are needed in order to } \\
\text { carry out an innovative } \\
\text { project. }\end{array}$ & $\begin{array}{l}\text { Saxonian Support Scheme } \\
\text { for R\&D Cooperation } \\
\text { (Schwartz et al. (2010)); } \\
\text { German Ministry of } \\
\text { Education and Research } \\
\text { Innovationsforen } \\
\text { (Dettman et al. (2012)) }\end{array}$ \\
\hline $\begin{array}{l}\text { Organisations based } \\
\text { outside the region or } \\
\text { the country to be } \\
\text { included in the } \\
\text { network }\end{array}$ & $\begin{array}{l}\text { External organizations } \\
\text { could help avoid } \\
\text { knowledge lock-in traps } \\
\text { to the extent that they are } \\
\text { able to bring new } \\
\text { knowledge and } \\
\text { competencies to the } \\
\text { partnership. }\end{array}$ & $\begin{array}{l}\text { American-Israeli R\&D } \\
\text { alliances supported by } \\
\text { Israel-US Binational } \\
\text { Industrial Research and } \\
\text { Development Foundation } \\
\text { (Bizan }(2003) \text { ) }\end{array}$ \\
\hline $\begin{array}{l}\text { Organisations can } \\
\text { participate in more } \\
\text { than one network at a } \\
\text { time }\end{array}$ & $\begin{array}{l}\text { Knowledge spillovers } \\
\text { from one project to } \\
\text { another are encouraged. } \\
\text { Policymakers facilitate the } \\
\text { emergence of a network } \\
\text { of innovative networks. }\end{array}$ & $\begin{array}{l}\text { EU framework } \\
\text { programmes (Breschi and } \\
\text { Cusmano (2004)); } \\
\text { Regional innovation } \\
\text { programmes in Italy } \\
\text { (Tuscany) (Russo and } \\
\text { Rossi (2009); Bellandi } \\
\text { and Caloffi (2010)) }\end{array}$ \\
\hline
\end{tabular}

and the requirement to include certain types of organisations, thus imposing a minimum amount of heterogeneity in the network's composition (henceforth referred to as 'minimum heterogeneity' requirement). We can expect these policy requirements to have both negative and positive effects on the participants' networking behaviour.

On the one hand, as previously noted, requirements may be instrumental in enhancing the participants' ability to form successful networks. It has been suggested that, as technologies become more complex and economic environments more uncertain, firms increasingly rely upon external sources of knowledge to support their technological development (Arora and Gambardella, 1990; Powell et al., 1996). Consequently, innovation activities have become more open and distributed, involving R\&D collaborations, integration of different knowledge modules, and transaction of intellectual property (Von Hippel, 1988; Chesbrough, 2003). Studies of both organisations and individuals have emphasized that interactions among heterogeneous actors are key sources of innovation (Fonseca, 2002; Nooteboom, 2004). Some features of such interactions are associated with greater likelihood to generate innovations and to foster long-lasting relationships that give rise to innovation cascades (Lane and Maxfield, 1997). The requirement to include a minimum number of partners could encourage the participants to expand their network of relationships and become acquainted with numerous organisations that can provide them with further networking opportunities. For example, in the case of firms trapped in relational lock-ins (Gargiulo and Benassi, 2000; Maurer and Ebers, 2006), this requirement could help increase the chance to meet new partners, access new knowledge and embark on new projects. This in turn could increase firms' likelihood to engage in subsequent networks, and to form larger networks. The requirement to include specific types of organisations, thus imposing a minimum amount of heterogeneity, could encourage participants to gain experience in initiating and managing relationships with partners possessing different competencies, cognitive frames and modes of operation. For example, for SMEs trapped in knowledge lock-ins or needing to renew their approach to innovation, contacts with universities could improve their chance to encounter new knowledge (Malerba, 2009) or to exploit existing knowledge (Schoonmaker and Carayannis, 2010; Arroyabe et al., 2015). However, it is precisely such companies that are most reluctant to create relationships (Kleinknecht and Reijnen, 1991). Collaborating with a university in the context of an innovative project could help SMEs learn the language, time frames, and practices of the university and to overcome some of the barriers that separate them. These processes may increase their likelihood to engage in subsequent heterogeneous networks.

On the other hand, policy requirements may have a negative effect on the performance of innovation networks, as they impose an additional layer of rules that may be misaligned with the participants' needs. If such rules are irrelevant, they may simply increase the transaction costs in the process of network formation. But such rules may even be detrimental, if they hamper the networks' innovative performance and learning processes. The minimum network size requirement can result in an increase in the number of participants that is not directly motivated by the needs of the project. This can create congestion and hamper communications among network members, thus reducing project performance. The heterogeneity requirement could lead to the inclusion of types of participants that are not necessary for the success of the project, and that may even have an adverse impact on it.

In what follows we will try to explore whether policy requirements induce participants to form networks with certain features to a greater extent than they would if such constraints were looser, or absent, and whether their effects on participants' networking behaviour manifest beyond the policy intervention in which they are applied.

\section{The policy interventions}

The empirical analysis focuses on a set of policies supporting networks of innovators implemented by the regional government of Tuscany. This regional government has been one of the most active promoters of innovation network policies in Italy, with a succession of tenders supported by European Regional Development funds (ERDF) since the early 2000s (Russo and Rossi, 2009; Bellandi and Caloffi, 2010). In particular, in the programming period 2000-2006 it promoted nine consecutive waves of four policy programmes aimed at supporting innovative projects carried out by networks of organisations: the Regional Programmes of Innovative Action (RPIA) implemented in 2002 (ITT Technological Innovation in Tuscany), and in 2006 (VINCI - Promoting innovation networks and virtual organisations), and two lines of the Single Programming Document of the Region, namely the line 1.7.1 and the line 1.7.2. All these programmes funded innovative projects implemented by consortia involving firms and other organisations. The duration of each consortium coincided with the duration of the funded project. The projects were carried out between 2002 and 2008. Our dataset is based primarily on the administrative records held and provided by the regional government agency that implemented the policy. It includes data on the participants in the eligible projects (location, NACE code, number of employees, number of project applications submitted to the programmes, number of applications that were funded, funding received, number of times they acted as project coordinators, participants or subcontractors), as well as on the characteristics of the project applications (policy wave and programme to which they were submitted, abstracts of the projects and the technology area they related to, whether they were funded or not, amount of funding granted, names and types of participants).

The policy initiatives were addressed to a regional economic context where SMEs with little R\&D activity, often operating in sectors affected by harsh international competition, are prevalent. In order to promote the upgrading of these firms' innovative skills and the adoption and diffusion of innovation in the region, the regional government supported the development of non-transitory forms of collaboration among micro enterprises, SMEs, large firms, universities, research centres, business services providers and other organisations acting as intermediaries (such as innovation centres). 
In the vision of policymakers, these programmes should have led to the development and strengthening of innovation clusters made of SMEs and large companies working together with innovation service providers, universities and other agents supporting innovation. Strongly inspired by the innovation system framework - which was dominant in the European innovation strategies of the time - the regional policymaker considered the emergence of such clusters as the first step towards the formation of an innovation system in Tuscany.

In some of the nine waves, two key types of requirements were imposed: a minimum degree of heterogeneity in the composition of the consortia (in particular, the specific nature of the organisations that should have been involved in the consortia was specified); and a minimum number of partner organisations. The latter requirement intended to involve a sufficient number of regional organisations so as to set the foundations for a regional innovation system, while the former intended to mobilize specific types of organisations that would play a role in this system (SPD 2002-2006 Objective 2 Tuscany Region, Line 1.7, RPIA 2002 and RPIA 2006).

We can group the nine policy waves into two distinct periods. The first period includes interventions launched between 2002 and 2005, it included the majority of waves (three programmes, divided into six waves $)^{3}$ and participants, and absorbed $45 \%$ of the resources assigned to network policies. Out of the six policy waves, five were characterized by the imposition of several requirements.

The second period started with interventions launched between 2006 and 2008. It included two programmes, divided into three waves. ${ }^{4}$ Interestingly, the last three waves had not been planned at the beginning of the programming period. Rather, the regional administration was able to procure additional funds that enabled it to implement further interventions. In these three waves, no requirements on the networks' composition were imposed.

Table 2 shows the requirements characterizing the different waves. These requirements were in line with the policymaker's objectives, which were to promote the realisation of successful innovation processes and to support learning processes on the part of the participants, SMEs in particular. In the policymakers' intentions (SPD 2002-2006 Objective 2 Tuscany Region, Line 1.7, RPIA 2002 and RPIA 2006), the heterogeneity requirements were instrumental in creating connections between organisations that would not have otherwise collaborated and in promoting the diffusion of knowledge and technology to those organisations that were perceived to be weaker elements in the regional innovation system: by requiring that networks involved both knowledge-intensive organisations (universities, public and private research centres, innovation centres) and partners that were less knowledge-intensive and less accustomed to engaging in collaborative innovation (micro enterprises and SMEs), the aim was to foster the transfer of advanced technologies and organisational knowledge from the former to the latter. The minimum network size requirements were expected to induce those organisations that were already part of established networks to open up their partnerships to new organisations, preventing them from locking into stable and closed communities.

According to the regional policy-makers and programme managers we interviewed, ${ }^{5}$ the requirements were included in the policies for

\footnotetext{
3 It included: the Regional Programme of Innovative Action issued in 2002 (labelled as 2002_ITT in what follows); the SPD line 171 - 'programme 1.7.1' - launched in 2002 (2002_171), in 2004 (two waves: 2004_171 and 2004_171E, targeting environmental protection technologies), in 2005 (2005_171); the SPD line 172 - 'programme 1.7.2' - issued in 2002 (2002_172).

4 The Regional Programme of the Innovative Action issued in 2006 (2006_VIN), and the waves 2007 and 2008 of the programme 171 (2007_171 and 2008_171).

${ }^{5}$ Interviews with the policymakers and to the managers of the programmes have been realized by the authors over the course of several years, and in particular in 2003-2004, 2005-2006, and 2007. The authors were involved in the evaluation of some of the programmes, namely the RPIA launched in 2002, the programme 171_2005, and the RPIA launched in 2006.
}

educational purposes and in particular with the aim of helping SMEs to expand their network of contacts for innovation and learn how to build relationships with universities, service providers, and other organisations.

Overall, the nine waves were assigned almost $€ 37$ million, representing around $40 \%$ of the total funds spent on regional innovation policies in that programming period. Half of these funds were assigned to waves funded at 100\% (non-repayable subsidies), while the rest was administered through co-funding (with shares of non-repayable subsidies ranging from $75 \%$ to $85 \%$ of admissible costs). Through the nine waves, 298 project proposals were considered eligible for funding, and 168 of these were funded. All projects were peer reviewed and assigned a score, which formed the basis for the decision whether to grant funding. The total number of different organisations that were involved in funded project proposals in the nine waves was 1121, a subset of which (352) had taken part in more than one project proposal. Since many waves allowed each organisation to participate in more than one project, the number of different participation instances amounted to 2003.

In our analysis we consider the results of requirements on the networking behaviour of the 819 organisations that participated in the five waves in the period 2002-2005 where requirements were imposed (waves 2002_ITT, 2002_171, 2002_172, 2004_171,2005_171, as shown in Table 2). ${ }^{6}$ Some of these organizations (201) went on to participate also in waves in the period 2006-2008. ${ }^{7}$ Table 3 shows the number and distribution by type of participating organisations in the periods considered. ${ }^{8}$

\section{The empirical strategy}

After describing in greater detail the structure of the policy waves, and after presenting some general descriptive statistics on the participating organisations, we move on to exploring the results of the policy requirements on the participants' networking behaviour. As mentioned previously, we focus both on the immediate results produced by the presence of the requirements, and on the subsequent effects of the requirements on the characteristics of networks that were submitted to later policy waves, in which requirements were absent.

As for the analysis of the immediate results, which will be discussed in Section 5.1, we focus on the effects of requirements on the individual networking behaviour of the 819 organisations participating in policy waves during the first period (2002-2005), by checking whether the average intensity of the policy requirements imposed during that period affected the average heterogeneity and size of the networks that each organisation participated in. Obviously, the projects applying for funding must comply with the requirements imposed by the policies. Therefore, we expect that the greater the required heterogeneity and size of the networks an organisation participates in, the greater the actual heterogeneity and size of its networks.

In order to verify whether this is true, we run two regressions where the actual heterogeneity (Model 1) and average size (Model 2) of an organisation's networks in the first period (avghet_0205 and avgsize_0205) are explained by the variables representing the average minimum heterogeneity (avgminhet) and the average minimum size (avgminsize) of the networks the organisation participated in, as

\footnotetext{
${ }^{6}$ We have excluded wave 2004_171E since it was the only wave in the period 2002 2005 in which no requirements on the networks' composition and size were imposed. This wave was focused only on environmental issues and funded projects of very limited duration (maximum 4 months).

7 Since the fulfillment of minimum size and heterogeneity requirements was a prerequisite in order to be considered eligible for funding, and since in some waves network size and heterogeneity contributed to the projects' ranking, we decided to focus only on the organisations that took part in funded projects, in order to avoid biases arising from the policymakers' selection process. However, we have found that the results presented in section 5 broadly hold also if we run the same analysis on the set of funded and nonfunded projects (the latter were eligible for funding, having fulfilled all the policy requirements, but they were not funded due to having received lower peer review scores).

8 The 34 organisations that only participated in wave 2004_171E are excluded from the analysis.
} 
Table 2

Types of requirements in the different waves.

\begin{tabular}{|c|c|c|c|c|c|c|}
\hline \multirow[b]{3}{*}{ Wave } & \multirow[b]{3}{*}{ Policy programme } & \multicolumn{5}{|c|}{ Type of requirements: } \\
\hline & & \multirow{2}{*}{$\begin{array}{l}\text { Minimum size of } \\
\text { the partnership }\end{array}$} & \multicolumn{4}{|c|}{ Minimum number of: } \\
\hline & & & SMES & Research organisations & Innovation centres & Local governments \\
\hline 2002_ITT & RPIA 2002 & 5 & 4 & 1 & & \\
\hline 2002_171 & SPD line 171 & 5 & 4 & & 1 & \\
\hline 2002_172 & SPD line 172 & 6 & 4 & & 1 & 1 \\
\hline 2004_171 & SPD line 171 & 4 & 1 & & & \\
\hline 2004_171E & SPD line 171 & & & & & \\
\hline 2005_171 & SPD line 171 & 10 & 5 & 1 & & 1 \\
\hline 2006_VIN & RPIA 2006 & & & & & \\
\hline 2007_171 & SPD line 171 & & & & & \\
\hline 2008_171 & SPD line 171 & & & & & \\
\hline
\end{tabular}

mandated by the policy requirements. These are average values. In fact, as the observed agents can take part in more than one project in the same period, the individual measure refers to the heterogeneity and size, on average, of the participated projects.

We measure the heterogeneity of each project network as the reciprocal of the Herfindahl index computed on the shares of participants belonging to each of nine categories (as listed in Table 3 ). ${ }^{9}$ The size of a network is measured by the number of participating organisations. Moreover, we measure the minimum heterogeneity requirement of each project network as the reciprocal of the Herfindahl index computed on the share of each type of participants required in the relevant wave (as indicated in columns 4-7 of Table 2), while the minimum size requirement of each project network is measured using the minimum number of partners required in the relevant wave (as indicated in column 3 of Table 2).

We also include four variables capturing the organisation's networking capabilities: the ability to put together successful applications (the number of funded projects the organisation participated in, nprojects_0205, the share of project proposals presented that were funded, sharefunded_0205) and the ability to take on a central role in the projects (the average funding per project the organisation was able to procure, avgfunding_0205, whether the organisation coordinated any funded projects, coord_0205). We control for the organisation's type and technological specialization of the projects in which was involved (share of projects in each technology area). We include these variables because, together with the existence of policy requirements, they can help to explain the heterogeneity and the size of the networks.

The models are estimated in the following linear form:

$y_{i}=c+\beta_{1 i}$ avgminhet $_{i}+\beta_{2 i}$ avgminsize $_{i}+\sum_{j} \delta_{j} N E T_{j i}+\sum_{k} \gamma_{k} O R G_{k i}+v_{i}$

where $y_{i}$ is the dependent variable (either avghet_0205 in Model 1 or avgsize_0205 in Model 2), avgminhet and avgminsize are respectively the average minimum heterogeneity and the average minimum size of the networks the organisation participated in during 2002-2005, $N E T_{j}$ is a set of four variables measuring the networking capabilities of the organisation during 2002-2005, $O R G_{k}$ is a set of variables capturing organisational characteristics (seven dummy variables capturing the

\footnotetext{
9 The reciprocal of the Herfindahl index (Herfindahl, 1982) computed for each project is:

$1 / H_{j}=1 /\left(\sum_{i}\left(x_{j i} / X_{i}^{2}\right)\right.$

where $x_{j i}$ is the number of organisations of type $i$ participating in project $j$, and $X_{i}$ is the total number of organisations participating in project $j$. This index quantifies how broad is the range of different types of organisations that participate in the project, and the relative weight of each type: the more 'equal' the shares, the higher is the index. A low value of $1 / H_{j}$ implies that the project is less heterogeneous while a high value implies that the project is more heterogeneous. The index takes values between 1 and $n$, which is the overall number of types (in this case, the index has an upper bound at $\mathrm{n}=9$ ).
}

organisation's type and ten variables capturing the organisation's technological specialization), and $v_{i}$ is an independent and identically distributed normal error term.

Table 4 reports the main descriptive statistics on the variables used in these models. The correlation matrix between these variables is reported in Appendix 1.

In terms of subsequent results, discussed in Section 5.2, we test whether the policy requirements in the first period (2002-2005) impacted on the participants' networking behaviour in the second period (2006-2008), when no requirements were imposed on the networks' composition.

We consider the set of 201 organisations that participated in both the first and the second periods and we examine whether the average required heterogeneity and size of the organization's funded project proposals in the first period influenced the average heterogeneity avghet_0608 - (Model 3) and the average size - avgsize_0608 (Model 4) of the project proposals funded in the second period. We control for four variables capturing the organisation's networking capabilities (the number of funded projects the organisation participated in, nprojects_0608, the share of project proposals presented that were funded, sharefunded_0608, the average funding per project the organisation was able to procure, avgfunding_0608, the share of funded projects which the organisation coordinated, sharecoord_0608), and for the organisation's type and technological specialization (share of projects in each technology area).

The models are estimated in the following linear form:

$y_{i}=c+\beta_{1 i}$ avgminhet $_{i}+\beta_{2 i}$ avgminsize $_{i}+\sum_{j} \delta_{j} N E T_{j i}+\sum_{k} \gamma_{k} O R G_{k i}+v_{i}$

where $y_{i}$ is the dependent variable (either avghet_0608 in Model 3 or avgsize_0608 in Model 4), avgminhet and avgminsize are respectively the average minimum heterogeneity and the average minimum size of the networks the organisation participated in during 2002-2005, $N E T_{j}$ is the set of four variables measuring the networking capabilities of the organisation during 2006-2008, $O R G_{k}$ is a set of variables capturing organisational characteristics (the same as in Models 1 and 2), and $v_{i}$ is an independent normal error term.

Table 5 reports the main descriptive statistics on the variables used in these models. The correlation matrix between these variables is reported in Appendix 2.

\section{Results}

\subsection{The immediate results of policy requirements}

The following Fig. 1 shows the heterogeneity and size of networks in a scatter diagram that distinguishes between waves with and without requirements. This representation shows that the size and heterogeneity of networks were, on average, greater when requirements were present (the average network size was 19.09 in waves with 
Table 3

Participants by type of organisation.

\begin{tabular}{|c|c|c|c|c|c|c|}
\hline \multirow[t]{2}{*}{ Type of organisation } & \multicolumn{2}{|c|}{$\begin{array}{l}5 \text { waves with policy requirements, } \\
2002-2005\end{array}$} & \multicolumn{2}{|c|}{$\begin{array}{l}3 \text { waves without policy } \\
\text { requirements, 2006-2008 }\end{array}$} & \multicolumn{2}{|c|}{$\begin{array}{l}5 \text { waves with policy requirements, } \\
2002-2005 \text {, and } 3 \text { waves without } \\
\text { policy requirements } 2006-2008\end{array}$} \\
\hline & n. participants & $\%$ & n. participants & $\%$ & n. participants & $\%$ \\
\hline Enterprise (Ent) & 471 & $57.51 \%$ & 260 & $55.44 \%$ & 72 & $35.82 \%$ \\
\hline Local business association (LA) & 71 & $8.67 \%$ & 33 & $7.04 \%$ & 23 & $11.44 \%$ \\
\hline University or PRO (Uni) & 68 & $8.30 \%$ & 47 & $10.02 \%$ & 27 & $13.43 \%$ \\
\hline Local government (LG) & 65 & $7.94 \%$ & 28 & $5.97 \%$ & 18 & $8.96 \%$ \\
\hline Business service provider (SP) & 58 & $7.08 \%$ & 43 & $9.17 \%$ & 20 & $9.95 \%$ \\
\hline Other public agency (Opub) & 32 & $3.91 \%$ & 16 & $3.41 \%$ & 9 & $4.48 \%$ \\
\hline Innovation centre (IC) & 31 & $3.79 \%$ & 21 & $4.48 \%$ & 18 & $8.96 \%$ \\
\hline Private research company (PR) & 13 & $1.59 \%$ & 10 & $2.13 \%$ & 4 & $1.99 \%$ \\
\hline Chamber of commerce (CC) & 10 & $1.22 \%$ & 11 & $2.35 \%$ & 10 & $4.98 \%$ \\
\hline Total & 819 & $100.00 \%$ & 469 & $100.00 \%$ & 201 & $100.00 \%$ \\
\hline
\end{tabular}

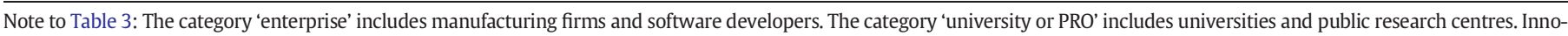

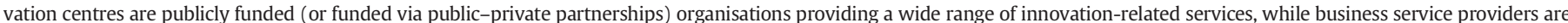

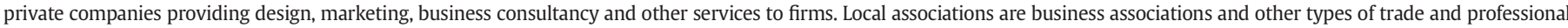
association among firms. 'Other public agencies' includes other public bodies such as, for instance, hospitals and medical clinics.

Table 4

Variables used in Models 1 and 2.

\begin{tabular}{|c|c|c|c|c|c|}
\hline \multirow[b]{2}{*}{ Variabile name } & \multirow[b]{2}{*}{ Variable description } & \multicolumn{4}{|c|}{ Number of observations: 819} \\
\hline & & Mean & $\sigma$ & Min & $\operatorname{Max}$ \\
\hline avgminhet & $\begin{array}{l}\text { Average minimum heterogeneity of networks as mandated by policy requirements. It is calculated as the reciprocal of the } \\
\text { Herfindahl index computed on the share of each type of participants required in the relevant wave (as indicated in } \\
\text { columns } 4-7 \text { of Table 2) }\end{array}$ & 1.71 & 0.19 & 1.00 & 2.00 \\
\hline avgminsize & $\begin{array}{l}\text { Average minimum size of networks as mandated by policy requirements. It is calculated as the minimum number of } \\
\text { partners required in the relevant wave (as indicated in column } 3 \text { of Table } 2 \text { ). }\end{array}$ & 8.24 & 2.24 & 4.00 & 10.00 \\
\hline avghet_0205 & $\begin{array}{l}\text { Average heterogeneity of funded networks the organisation participated in, 2002-2005. It is calculated as the reciprocal of } \\
\text { the Herfindahl index computed on the shares of participants belonging to each of nine categories presented in Table } 3 \text {. }\end{array}$ & 3.41 & 1.02 & 1.18 & 5.95 \\
\hline avgsize_0205 & $\begin{array}{l}\text { Average size of funded networks the organisation participated in, 2002-2005. The size of the network is measured by the } \\
\text { number of participating organisations. }\end{array}$ & 22.18 & 6.88 & 4.00 & 37.00 \\
\hline nprojects_0205 & Overall number of funded projects the organisation participated in, 2002-2005 & 1.51 & 1.28 & 1.00 & 14.00 \\
\hline sharefunded_0205 & Share of funded projects in 2002-2005 & 0.89 & 0.21 & 0.13 & 1.00 \\
\hline avgfunding_0205 & Average funding per project obtained by the organisation in $2002-2005$ & 8017 & 17,500 & 0.00 & 266,425 \\
\hline coord_0205 & Dummy equal to 1 if the organisation has coordinated any funded projects in 2002-2005 & 0.06 & 0.25 & 0.00 & 1.00 \\
\hline Ent & Dummy equal to 1 if the organisation is an Enterprise & 0.58 & 0.49 & 0.00 & 1.00 \\
\hline$L A$ & Dummy equal to 1 if the organisation is a Local business association & 0.09 & 0.28 & 0.00 & 1.00 \\
\hline Uni & Dummy equal to 1 if the organisation is a University or PRO & 0.08 & 0.28 & 0.00 & 1.00 \\
\hline$L G$ & Dummy equal to 1 if the organisation is a Local government & 0.08 & 0.27 & 0.00 & 1.00 \\
\hline$S P$ & Dummy equal to 1 if the organisation is a Business service provider & 0.07 & 0.26 & 0.00 & 1.00 \\
\hline Opub & Dummy equal to 1 if the organisation is an Other public agency & 0.04 & 0.19 & 0.00 & 1.00 \\
\hline IC & Dummy equal to 1 if the organisation is an Innovation centre & 0.04 & 0.19 & 0.00 & 1.00 \\
\hline shareICT & Share of projects in ICT & 0.52 & 0.43 & 0.00 & 1.00 \\
\hline shareOpto & Share of projects in optoelectronics & 0.11 & 0.29 & 0.00 & 1.00 \\
\hline shareMEch & Share of projects in mechanics & 0.05 & 0.18 & 0.00 & 1.00 \\
\hline shareOrgChem & Share of projects in organic chemistry & 0.04 & 0.16 & 0.00 & 1.00 \\
\hline shareBiotech & Share of projects in biotechnology & 0.05 & 0.19 & 0.00 & 1.00 \\
\hline shareNew & Share of projects in new technologies & 0.05 & 0.19 & 0.00 & 1.00 \\
\hline shareMulti & Share of projects in multiple areas & 0.02 & 0.11 & 0.00 & 1.00 \\
\hline shareNano & Share of projects in nanotechnology & 0.03 & 0.17 & 0.00 & 1.00 \\
\hline shareGeo & Share of projects in geothermal energy & 0.01 & 0.05 & 0.00 & 0.50 \\
\hline shareOther & Share of projects in other areas & 0.02 & 0.11 & 0.00 & 1.00 \\
\hline
\end{tabular}

requirements, and 7.81 in waves without requirements; the average network heterogeneity was 3.38 in waves with requirements and 2.54 in waves without requirements). In waves with requirements, however, network heterogeneity exhibited lower variability in relation to the mean and displayed a smaller range of values, than in waves without requirements; the opposite occurred for network size, which was more variable and displayed a larger range of values in waves with requirements than in waves without requirements.

To assess the immediate results of policy requirements on organisations' networking behaviour, we have implemented two econometric models that take organisations as the units of analysis and explore the influence of the average minimum heterogeneity (avgminhet) and the average minimum size (avgminsize) of the projects the organisation participated in, as mandated by the policy requirements, on, respectively, the average heterogeneity (Model 1) and average size (Model 2) of its networks. The results are reported in Table 6. ${ }^{10}$

The regressions on the variables avghet_0205 and avgsize_0205 show that policy requirements significantly influence the heterogeneity and size of the networks each organisation participates in: the variable avgminsize has a positive and significant coefficient in both Model 1 and Model 2, indicating that participating in networks that, on average, have higher minimum size requirements leads organisations to

\footnotetext{
10 The models were estimated with robust standard errors due to the Breusch-Pagan tests rejecting the null hypothesis of homoscedasticity in Model 2 (Chi2 $=12.6$, pvalue $=0.001$ ) although not in Model 1 (Chi2 $=1.6$, p-value $=0.21$ ). Although there is a relatively high correlation between avgminhet and avgminsize (0.74) the analysis of the variance inflation factors for these variables ( 2.45 and 2.84 respectively) suggests that multicollinearity is not problematic in these models.
} 
Table 5

Variables used in Models 3 and 4

\begin{tabular}{|c|c|c|c|c|c|}
\hline \multirow[b]{2}{*}{ Variabile name } & \multirow[b]{2}{*}{ Variable description } & \multicolumn{4}{|c|}{ Number of observations: 201} \\
\hline & & Mean & $\sigma$ & Min & Max \\
\hline avgminhet & $\begin{array}{l}\text { Average minimum heterogeneity of projects as mandated by policy requirements. It is calculated as the reciprocal of the } \\
\text { Herfindahl index computed on the share of each type of participants required in the relevant wave (as indicated in } \\
\text { columns } 4-7 \text { of Table } 2 \text { ). }\end{array}$ & 1.74 & 0.16 & 1.00 & 2.00 \\
\hline avgminsize & $\begin{array}{l}\text { Average minimum size of projects as mandated by policy requirements. It is calculated as the minimum number of } \\
\text { partners required in the relevant wave (as indicated in column } 3 \text { of Table } 2 \text { ). }\end{array}$ & 8.69 & 1.77 & 4.00 & 10.00 \\
\hline avghet_0608 & $\begin{array}{l}\text { Average heterogeneity of funded networks the organisation participated in, 2006-2008. It is calculated as the reciprocal } \\
\text { of the Herfindahl index computed on the shares of participants belonging to each of nine categories presented in Table } 3 \text {. }\end{array}$ & 2.85 & 1.15 & 1.00 & 6.76 \\
\hline avgsize_0608 & $\begin{array}{l}\text { Average size of funded networks the organisation participated in, 2006-2008. The size of the network is measured by the } \\
\text { number of participating organisations. }\end{array}$ & 9.95 & 3.23 & 4.00 & 18.00 \\
\hline nprojects_0608 & Number of funded projects the organisation participated in 2006-2008 & 1.83 & 1.26 & 1.00 & 8.00 \\
\hline sharefunded_0608 & Share of funded projects in 2006-2008 & 0.87 & 0.22 & 0.20 & 1.00 \\
\hline avgfunding_0608 & Average funding per project obtained by the organisation in 2006-2008 & 32,645 & 39,697 & 0.00 & 240,793 \\
\hline coord_0608 & Dummy equal to 1 if the organisation has coordinated any funded projects in 2006-2008 & 0.23 & 0.42 & 0.00 & 1.00 \\
\hline Ent & Dummy equal to 1 if the organisation is an Enterprise & 0.36 & 0.48 & 0.00 & 1.00 \\
\hline$L A$ & Dummy equal to 1 if the organisation is a Local business association & 0.11 & 0.32 & 0.00 & 1.00 \\
\hline Uni & Dummy equal to 1 if the organisation is a University or PRO & 0.13 & 0.34 & 0.00 & 1.00 \\
\hline$L G$ & Dummy equal to 1 if the organisation is a Local government & 0.09 & 0.29 & 0.00 & 1.00 \\
\hline$S P$ & Dummy equal to 1 if the organisation is a Business service provider & 0.10 & 0.30 & 0.00 & 1.00 \\
\hline Opub & Dummy equal to 1 if the organisation is an Other public agency & 0.04 & 0.21 & 0.00 & 1.00 \\
\hline IC & Dummy equal to 1 if the organisation is an Innovation centre & 0.09 & 0.29 & 0.00 & 1.00 \\
\hline shareICT & Share of projects in ICT & 0.48 & 0.29 & 0.00 & 1.00 \\
\hline shareOpto & Share of projects in optoelectronics & 0.08 & 0.21 & 0.00 & 1.00 \\
\hline shareMEch & Share of projects in mechanics & 0.07 & 0.14 & 0.00 & 0.67 \\
\hline shareOrgChem & Share of projects in organic chemistry & 0.02 & 0.07 & 0.00 & 0.50 \\
\hline shareBiotech & Share of projects in biotechnology & 0.04 & 0.14 & 0.00 & 1.00 \\
\hline shareNew & Share of projects in new technologies & 0.06 & 0.15 & 0.00 & 1.00 \\
\hline shareMulti & Share of projects in multiple areas & 0.02 & 0.07 & 0.00 & 0.50 \\
\hline shareNano & Share of projects in nanotechnology & 0.01 & 0.04 & 0.00 & 0.40 \\
\hline shareGeo & Share of projects in geothermal energy & 0.01 & 0.05 & 0.00 & 0.50 \\
\hline shareOther & Share of projects in other areas & 0.01 & 0.08 & 0.00 & 0.67 \\
\hline
\end{tabular}

form larger and more heterogeneous networks. Instead, the variable avgminhet has a negative and significant coefficient in both Model 1 and Model 2, indicating that participating in networks that, on average, have higher minimum heterogeneity requirements leads organisations to form less heterogeneous and smaller networks. This is a counterintuitive result that we discuss in greater detail later.

Firms are involved in less heterogeneous networks, while business service providers take part in more heterogeneous ones. This is consistent with business service providers playing an intermediary role between other organisations in the networks (Caloffi et al., 2015) and hence being instrumental in supporting greater heterogeneity. Firms instead entered the networks mainly as technology users, sharing this role with other firms. Local associations, innovation centres, local governments, universities and other public organisations are involved in larger

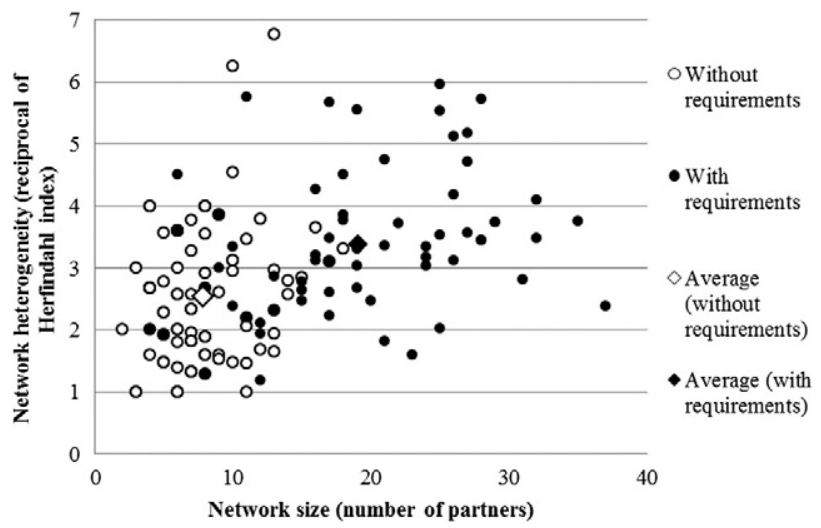

Fig. 1. Size and heterogeneity of project networks, grouped according to presence or absence of requirements. networks. Greater success in preparing project applications (share of funded projects) and having a more central role in the projects (average funding) are linked to lower heterogeneity and smaller size. This suggests that, in this first period, participants that were more central, and presumably more experienced, in project management preferred joining more homogeneous and smaller networks, despite the opposite incentives provided by the policy.

\subsection{The subsequent results of policy requirements}

The results of Models 3 and 4 are reported in Table $7 .{ }^{11}$ Here, we consider the set of 201 organisations that participated in both periods (2002-2005 and 2006-2008) and we explore the effects of the average minimum heterogeneity (avgminhet) and the average minimum size (avgminsize) of the projects the organisation participated in during the first period, as required by the policy requirements, on the average heterogeneity (avghet_0608) and average size (avgsize_0608) of its networks in the second period.

Models 3 and 4 suggest that the average minimum heterogeneity and/or average minimum size requirements did not influence the average heterogeneity or the average size of an organization's networks in the second period. This may suggest that organisations may not consider heterogeneity per se as a valuable attribute of project networks, but rather only value when it is indeed necessary for the project's success.

Considering both models, greater average funding is negatively associated with average network heterogeneity and average network size,

\footnotetext{
11 The models were estimated with robust standard errors due to the Breusch-Pagan tests rejecting the null hypothesis of homoscedasticity in Model 3 (Chi2 $=6.40$, pvalue $=0.01$ ) although not in Model 4 (Chi2 $=0.91$, $\mathrm{p}$-value $=0.34$ ). Although there is a relatively high correlation between avgminhet and avgminsize (0.62) the analysis of the variance inflation factors for these variables ( 1.90 and 2.09 respectively) suggests that multicollinearity is not problematic in these models.
} 
Table 6

Estimates for Models 1 and 2.

\begin{tabular}{|c|c|c|}
\hline \multirow{3}{*}{ Dependent VARIABLE } & Model 1 & \multirow{2}{*}{$\frac{\text { Model } 2}{\text { avgsize_0205 }}$} \\
\hline & avghet_0205 & \\
\hline & $\begin{array}{l}\text { Coefficient (Robust } \\
\text { Standard Error) }\end{array}$ & $\begin{array}{l}\text { Coefficient (Robust } \\
\text { Standard Error) }\end{array}$ \\
\hline avgminhet & $\begin{array}{l}-0.493^{* *} \\
(0.244)\end{array}$ & $\begin{array}{l}-9.765^{* * *} \\
(2.142)\end{array}$ \\
\hline avgminsize & $\begin{array}{l}0.246^{* * *} \\
(0.0211)\end{array}$ & $\begin{array}{l}1.852^{* * *} \\
(0.177)\end{array}$ \\
\hline nprojects_0205 & $\begin{array}{l}-0.0136 \\
(0.0185)\end{array}$ & $\begin{array}{c}-0.0744 \\
(0.107)\end{array}$ \\
\hline sharefunded_0205 & $\begin{array}{l}-0.565^{* * *} \\
(0.202)\end{array}$ & $\begin{array}{l}-0.593 \\
(1.469)\end{array}$ \\
\hline avgfunding_0205 & $\begin{array}{c}-0.000 \\
(0.000)\end{array}$ & $\begin{array}{c}-0.000^{* *} \\
(0.000)\end{array}$ \\
\hline coord_0205 & $\begin{array}{l}-0.170 \\
(0.115)\end{array}$ & $\begin{array}{l}-0.805 \\
(0.726)\end{array}$ \\
\hline Ent & $\begin{array}{c}-0.462^{* * *} \\
(0.146)\end{array}$ & $\begin{array}{c}1.500 \\
(1.145)\end{array}$ \\
\hline LA & $\begin{array}{l}-0.114 \\
(0.161)\end{array}$ & $\begin{array}{l}2.675^{* *} \\
(1.208)\end{array}$ \\
\hline Uni & $\begin{array}{l}-0.132 \\
(0.166)\end{array}$ & $\begin{array}{l}2.418^{*} \\
(1.257)\end{array}$ \\
\hline LG & $\begin{array}{l}-0.280 \\
(0.181)\end{array}$ & $\begin{array}{l}4.265^{* * *} \\
(1.204)\end{array}$ \\
\hline SP & $\begin{array}{l}0.370^{* *} \\
(0.176)\end{array}$ & $\begin{array}{c}0.615 \\
(1.406)\end{array}$ \\
\hline Opub & $\begin{array}{c}0.174 \\
(0.205)\end{array}$ & $\begin{array}{l}3.125^{* *} \\
(1.421)\end{array}$ \\
\hline IC & $\begin{array}{c}0.127 \\
(0.190)\end{array}$ & $\begin{array}{l}5.022^{* * *} \\
(1.634)\end{array}$ \\
\hline $\begin{array}{l}\text { Technology specializations } \\
\text { constant }\end{array}$ & $\begin{array}{c}\text { Significant } \\
2.806^{* * *} \\
(0.400)\end{array}$ & $\begin{array}{c}\text { Significant } \\
19.24^{* * *} \\
(3.551)\end{array}$ \\
\hline N. observations & 819 & 819 \\
\hline $\mathrm{F}$ & 32.98 & 27.56 \\
\hline Prob $>$ F & 0.000 & 0.000 \\
\hline R-squared & 0.416 & 0.370 \\
\hline
\end{tabular}

*** $\mathrm{p}<0.01,{ }^{* *} \mathrm{p}<0.05,{ }^{*} \mathrm{p}<0.1$.
Table 7

Estimates for Models 3 and 4.

\begin{tabular}{|c|c|c|}
\hline \multirow{3}{*}{ Dependent variable: } & Model 3 & \multirow{2}{*}{$\frac{\text { Model } 4}{\text { avgsize_0608 }}$} \\
\hline & avghet_0608 & \\
\hline & $\begin{array}{l}\text { Coefficient (Robust } \\
\text { Standard Error) }\end{array}$ & $\begin{array}{l}\text { Coefficient (Robust } \\
\text { Standard Error) }\end{array}$ \\
\hline avgminhet & $\begin{array}{l}-0.537 \\
(0.624)\end{array}$ & $\begin{array}{l}-0.667 \\
(2.025)\end{array}$ \\
\hline avgminsize & $\begin{array}{c}0.0889 \\
(0.0600)\end{array}$ & $\begin{array}{l}0.0294 \\
(0.189)\end{array}$ \\
\hline nprojects_0608 & $\begin{array}{l}-0.0667 \\
(0.0620)\end{array}$ & $\begin{array}{l}0.0732 \\
(0.169)\end{array}$ \\
\hline sharefunded_0608 & $\begin{array}{c}0.439 \\
(0.443)\end{array}$ & $\begin{array}{l}3.118^{* *} \\
(1.317)\end{array}$ \\
\hline avgfunding_0608 & $\begin{array}{c}-0.000^{* * *} \\
(0.000)\end{array}$ & $\begin{array}{l}-0.000^{* *} \\
(0.000)\end{array}$ \\
\hline coord_0608 & $\begin{array}{c}0.203 \\
(0.254)\end{array}$ & $\begin{array}{l}-0.265 \\
(0.722)\end{array}$ \\
\hline Ent & $\begin{array}{c}0.398 \\
(0.404)\end{array}$ & $\begin{array}{c}-0.0180 \\
(0.594)\end{array}$ \\
\hline LA & $\begin{array}{l}1.155^{* *} \\
(0.450)\end{array}$ & $\begin{array}{l}-0.332 \\
(0.925)\end{array}$ \\
\hline Uni & $\begin{array}{l}1.397^{* * *} \\
(0.455)\end{array}$ & $\begin{array}{c}0.627 \\
(0.839)\end{array}$ \\
\hline LG & $\begin{array}{l}1.216^{* * *} \\
(0.448)\end{array}$ & $\begin{array}{l}-0.336 \\
(0.781)\end{array}$ \\
\hline SP & $\begin{array}{l}1.116^{* *} \\
(0.464)\end{array}$ & $\begin{array}{c}-0.0563 \\
(0.975)\end{array}$ \\
\hline Opub & $\begin{array}{l}1.640^{* * * *} \\
(0.579)\end{array}$ & $\begin{array}{l}-0.824 \\
(1.003)\end{array}$ \\
\hline IC & $\begin{array}{l}1.208^{* * *} \\
(0.454)\end{array}$ & $\begin{array}{l}-0.950 \\
(0.954)\end{array}$ \\
\hline $\begin{array}{l}\text { Technology specializations } \\
\text { constant }\end{array}$ & $\begin{array}{c}\text { Significant } \\
2.200^{*} \\
(1.184)\end{array}$ & $\begin{array}{c}\text { Significant } \\
7.364^{* *} \\
(3.481)\end{array}$ \\
\hline N. observations & 201 & 201 \\
\hline $\mathrm{F}$ & 6.913 & 2.804 \\
\hline Prob $>$ F & 0.000 & 0.000 \\
\hline R-squared & 0.323 & 0.230 \\
\hline
\end{tabular}

${ }^{* * *} \mathrm{p}<0.01,{ }^{* *} \mathrm{p}<0.05,{ }^{*} \mathrm{p}<0.1$. like in Models 1 and 2, while having a greater share of funded project proposals is positively associated with average network heterogeneity and average network size. Like in the previous period, organisations that took on a more central role in the management of the projects tended to be involved in smaller and less heterogeneous networks, while in the second period organisations that were more successful at preparing project applications tended to take part in larger and more heterogeneous networks. These findings could suggest the presence of a core of leading actors that often collaborated across the different policy waves, surrounded by a number of very active organisations who continued to start new networks. This structure would be consistent with the oligarchic network identified by Breschi and Cusmano (2004) in the case of the EU Framework Programmes. Finally, universities, innovation centres, local governments, associations, business service providers and other public agencies on average participated in more heterogeneous networks.

\section{Discussion}

Our empirical analysis has shown that the imposition of requirements on the size and composition of networks to be submitted for funding had a controversial influence on the characteristics of the networks that were actually formed. Obviously, in order to be eligible for funding, the agents tried to meet the policy requirements. However, this effect was limited to the waves in which the requirement was imposed and did not extend to the subsequent waves. In particular, the minimum network size requirement appears to have induced organisations to form larger and more heterogeneous networks: the greater, on average, the size of the network that was required, the larger and more heterogeneous were, on average, the networks the organisation participated in. Such requirement appears to have pushed organisations to network with a greater number of other organisations and with a more varied range of organisations as well. Once the requirement was removed in the second period, however, organisations returned to forming smaller networks (as shown in Fig. 1, average network size was smaller in programmes without requirements) and indeed the average minimum size requirement imposed in the first period did not affect the average size of an organisation's networks in the second period. This suggests that participants did not find that being involved in larger networks to be, per se, was particularly valuable (this is confirmed by the fact that more experienced participants that took on a more central role in the projects, tended to be involved in smaller networks, on average), although being part of larger networks in the first period allowed them to establish contacts which may provide useful in other contexts and at future points in time.

The immediate result that participation in programmes with tighter minimum heterogeneity requirements is negatively correlated with the heterogeneity of the networks presented can appear counterintuitive. A possible explanation for this apparently puzzling result is that the specification of more stringent requirement may have discouraged participants from including in their networks organisations that were different from the types recommended by the policymaker; that is, when confronted with very specific requirements, participants followed the guidelines for network composition quite closely and avoided including other types of organisations. This, paradoxically, led them to form networks that were less heterogeneous than those they may have formed had the requirement been looser. This interpretation is consistent with the observation that in programmes where heterogeneity 
requirements were present, the project networks' heterogeneity indexes had smaller variability and range (see Fig. 1) leading us to suggest that one of the effects of the heterogeneity requirements might have been to reduce the variety in the composition of the different networks.

This requirement seems to have been interpreted as a guideline to follow closely rather than a minimum threshold, reducing experimentation and leading organisations to adhere strictly to the recommended requirement. Once the requirement was removed in the second period, organisations experimented with a greater variability in network composition, and indeed there is no effect on the average heterogeneity of an organisation's networks in the second period of the average heterogeneity requirement imposed in the first.

Participants did not appear to consider heterogeneity as a desirable network feature. This is in line with previous research showing that organisations prefer to partner with similar agents (Caloffi et al., 2015). A certain degree of similarity, which allows organisations to develop a common understanding and a number of complementarities, has been linked to the creation of stable and successful R\&D consortia (Bizan, 2003; Häusler et al., 1994; Branstetter and Sakakibara, 2002). On average, any behavioural change seems to be limited to the waves in which these requirements were implemented. This is not to say that these policies did not have any effect, because the average values can conceal very different individual behaviours. In fact, as shown in a more detailed analysis on funded agents' dyadic relationships, individuals seem to have reorganized some of their innovative relationships with specific partners in the sense desired by policymakers (Caloffi et al., 2015). However, our findings appear to suggest that the imposition of simple requirements on network structure is not sufficient to permanently affect an organization's overall networking behaviour over time. This may be particularly true for projects that have small scale and short duration, since learning processes leading to behavioural changes within organisations may require a long time and the commitment of substantial resources. In the case we have presented, most organisations did not receive a large amount of funds (the average funding per project in the nine waves was about $€ 219,000$, with a minimum funding of $€ 20,000$ and a maximum funding of just over $€ 3$ million), and they only collaborated for a short time (the average duration of each project was just over 12 months, with a minimum duration of 3 months and a maximum duration of 26 months).

It must be noted that the study suffers from some limitations due to data availability. One key limitation is that we do not have information about the networking behaviour of the participating organisations outside of and beyond the policy programmes considered. To fully apprehend the behavioural additionality effects of the policies we should compare the organisations' behaviour with that of a control group of agents that did not take part in such interventions. Moreover, we do not have information about the actual performance of these networks, in order to analyse whether different types of network structures are actually associated with different economic and innovation performance. We are currently trying to extend our research in both of these directions.

\section{Conclusion}

This study has allowed us to identify some drawbacks and unintended effects that might emerge when attempting to design innovation networks by mandating their size and composition. Policymakers' objectives when setting such requirements were to foster interactions between organisations that might not have occurred spontaneously, and to provide these organisations with a funded platform (the project) in which to test the collaboration. As a consequence of this approach, it might be expected that, having appreciated the benefits of collaborating with many different partners, participating organisations would have continued to form large and heterogeneous networks without the need for further encouragement. However, we have found that this was not the case, as once the requirements were removed, organisations returned to forming smaller networks, and to using a variety of partnership arrangements beyond those mandated by the policy requirements.

We suggest that the problem with the ex ante definition of very specific requirements, such as the detailed prescription of the types of agents that must be included in the network, is that, while there is a general consensus on the benefits of heterogeneous networks, the nature of the agents that may best contribute to the partnership very much depends on the content of the project that the network intends to realize. The requirement to involve specific types of organisations may force participants to include types of partners that are not needed for the purposes of their project, creating unnecessary complications; our findings also suggest that they may discourage them from experimenting with different, possibly more appropriate, network compositions, a further disadvantage that had not been previously identified and which extends our theoretical understanding of the effects of policy requirements. In this case, the drawbacks of the heterogeneity requirement appear to have overcome its advantages. Looser requirements like the imposition of a minimum number of partners may have fewer drawbacks, since they still leave participants with some freedom to design their partnership according to their needs, but they still impose additional transaction costs and require the project resources to be spread to partners who may not be necessary for the project's success. Therefore, an immediate implication for policy design and management is that requirements should be used very sparingly, and in particular very specific requirements should be avoided, as they can be counterproductive to the objectives to foster network effectiveness, as well as learning and experimentation.

Instead, in order to support organisations' ability to interact with a broader and more heterogeneous set of collaborators, aspects that the theory stresses to be of fundamental importance, strategies other than the imposition of requirements on network structure may be more productive. For example, outreach actions could be implemented in order to inform organisations of the benefits of networking with other partners and to help them to exploit the opportunities offered by policy programmes. Alongside the funding of innovation networks, policymakers could design additional measures, in order to foster learning opportunities for the participants. For example, they could provide them with opportunities to meet other participating organisations, to engage in joint actions, to reflect on their networking experiences and to learn from other successful projects, and they could mediate communications between organisations of different types that find it difficult to work together. This suggests that policies for innovation networks should include - besides the selection, funding and ex post evaluation of innovation projects - a range of support activities designed to foster learning, which could be provided by the policymakers themselves, or delegated to experienced innovation intermediaries.

The findings also illustrate how investigating the behavioural effects of policies can bring useful insights, and should become a more frequent component of policy evaluation.

\section{Acknowledgements}

We are grateful to two anonymous reviewers whose comments have helped us to greatly improve the paper. We thank Dr. Albino Caporale, Dr. Emanuele Fabbri and their colleagues from Regione Toscana for their support in collecting and sharing the administrative data on which the analysis is based. For their comments on an early version of this paper, we thank Luca Andriani, Sylvie Occelli and the participants to the workshop "Complexity in the Real World: from Policy Intelligence to Intelligent Policy" (ECCS'12, Brussels). The views expressed in this article are those of the authors. 
Appendix 1. Correlation matrix between variables in Models 1 and $2(n=819)$

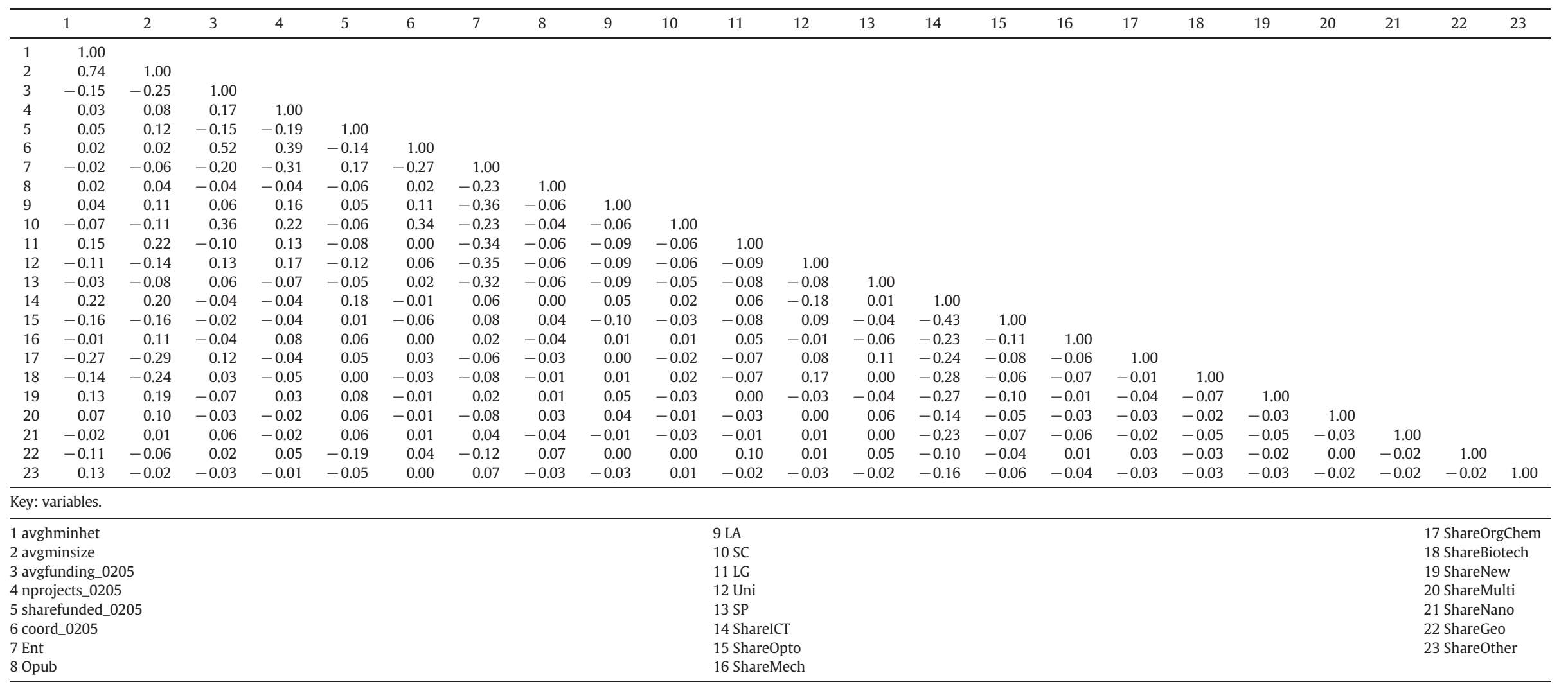


Appendix 2. Correlation matrix between variables in Models 3 and $4(n=201)$

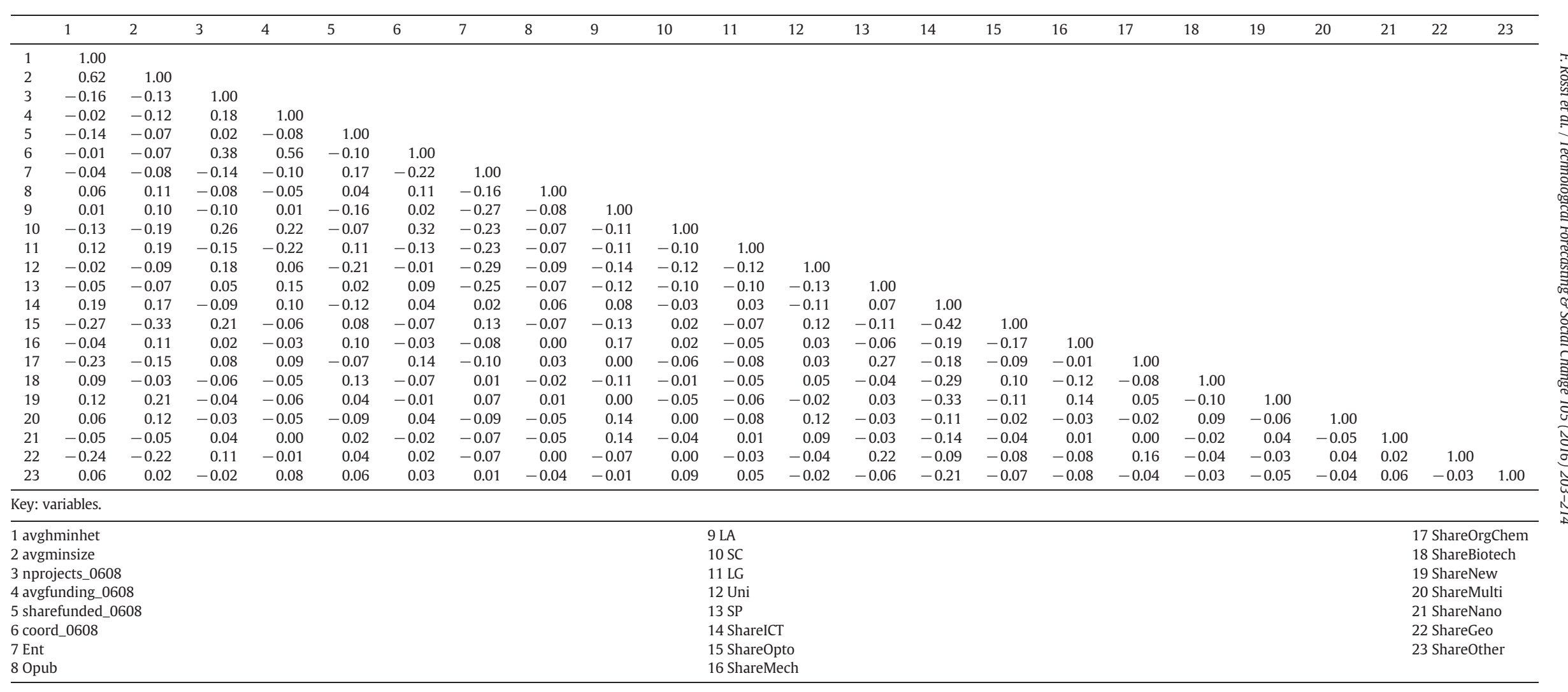




\section{References}

Antonioli, D., Marzucchi, A., Montresor, S., 2014. Regional innovation policy and innovative behaviour: looking for additional effects. Eur. Plan. Stud. 22 (1), 64-83.

Arora, A., Gambardella, A., 1990. The changing technology of technological change: general and abstract knowledge and the division of innovative labour. Res. Policy 23, 523-532.

Arroyabe, M.F., Arranz, N., Fdez de Arroyabe, J.C., 2015. R\&D partnerships: an exploratory approach to the role of structural variables in joint project performance. Technol. Forecast. Soc. Chang. 90, 623-634.

Bach, L., Matt, M., 2002. Rationale for Science \& Technology Policy. In: Georghiou, L., Rigby, J., Cameron, H. (Eds.), Assessing the Socio-Economic Impacts of the Framework Programme (ASIF). Report to European Commission DG Research, pp. 93-145.

Bach, L., Matt, M., 2005. From Economic Foundations to S\&T Policy Tools: A Comparative Analysis of the Dominant Paradigms. In: Llerena, P., Matt, M. (Eds.), Innovation Policy in a Knowledge-Based Economy: Theory and Practice. Springer, Berlin Heidelberg.

Bellandi, M., Caloffi, A., 2010. An analysis of regional policies promoting networks for innovation. Eur. Plan. Stud. 18 (1), 67-82.

Biggiero, L., Angelini, P.P., 2014. Hunting scale-free properties in R\&D collaboration networks: self-organization, power-law and policy issues in the European aerospace research area. Technol. Forecast. Soc. Chang. http://dx.doi.org/10.1016/j.techfore. 2014.04.009 ahead-of-print.

Bizan, O., 2003. The determinants of success of R\&D projects: evidence from AmericanIsraeli research alliances. Res. Policy 32 (9), 1619-1640.

Bougrain, F., Haudeville, B., 2002. Innovation, collaboration and SMEs internal research capacities. Res. Policy 31 (5), 735-747.

Branstetter, L., Sakakibara, M., 2002. When do research consortia work well and why? Evidence from Japanese panel data. Am. Econ. Rev. 92, 143-159.

Breschi, S., Cusmano, L., 2004. Unveiling the texture of a European research area: emergence of oligarchic networks under EU Framework Programmes. Int. J. Technol. Manag. 27 (8), 747-772.

Breschi, S., Malerba, F., 2009. ERA and the Role of Networks. In: Delanghe, H., Muldur, U., Soete, L. (Eds.), European Science and Technology Policy: Towards Integration or Fragmentation?Edward Elgar, Cheltenham.

Buisseret, T.J., Cameron, H.M., Georghiou, L., 1995. What difference does it make additionality in the public support of R\&D in large firms. Int. J. Technol. Manag. 10, 587-600.

Caloffi, A., Rossi, F., Russo, M., 2015. What makes SMEs more likely to collaborate? Analysing the role of regional innovation policy. Eur. Plan. Stud. 23 (7), 1245-1264.

Caloghirou, Y., Vonortas, N.S., Ioannides, S., 2004. European Collaboration in Research and Innovation. Business Strategy and Public Policy. Edward Elgar, Cheltenham.

Carlsson, B., Jacobsson, S., 1997. In search of useful public policies: key lessons and issues for policy makers. In: Carlsson, B. (Ed.), Technological Systems and Industrial Dynamics. Kluwer Academic Publishers, Dordrecht.

Chávez, S.M., 2011. Behavioural additionality in the context of regional innovation policy in Spain. Innov. Manag. Poliy Pract. 13 (1), 95-110.

Chesbrough, H., 2003. The era of open innovation. MIT Sloan Manag. Rev. 44 (3), 35-41.

Clarysse, B., Wright, M., Mustar, P., 2009. Behavioural additionality of R\&D subsidies: a learning perspective. Res. Policy 38 (10), 1517-1533.

Crespi, F., Quatraro, F., 2013. Introduction to the special section on: systemic technology policies: issues and instruments. Technol. Forecast. Soc. Chang. 80 (8), 1447-1449.

Cunningham, P., Ramlogan, R., 2012. The Effects of Innovation Network Policies, Manchester Institute of Innovation Research. Manchester Business School, University of Manchester.

Dettman, A., Von Proff, S., Brenner, T., 2012. Co-operation Over Distance? The Spatial Dimension of Inter-organisational Innovation Collaboration. WP Marburg Geography n.3.

Duso, T., Pennings, E., Seldeslachts, J., 2010. Learning dynamics in research alliances: a panel data analysis. Res. Policy 39 (6), 776-789.

Fier, A., Aschhoff, B., Löhlein, H., 2006. Behavioural Additionality of Public R\&D Funding in Germany, in Government R\&D Funding and Company Behaviour. Measuring Behavioural Additionality. OECD Publishing, Paris.

Fonseca, J., 2002. Complexity and Innovation in Organizations. Routledge, London.

Gargiulo, M., Benassi, M., 2000. Trapped in your own net? Network cohesion, structural holes, and the adaptation of social capital. Organ. Sci. 11 (2), 183-196.

Georghiou, L., 1998. Issues in the evaluation of innovation and technology policy. Evaluation 4, 37-51.

Gök, A., Edler, J., 2012. The use of behavioural additionality evaluation in innovation policy-making. Res. Eval. 21 (4), 306-318.

Hagedoorn, J., Link, A.N., Vonortas, N.S., 2000. Research partnerships. Res. Policy 29 (4), 567-586.

Häusler, J., Hohn, H.-W., Lütz, S., 1994. Contingencies of innovative networks: a case study of successful R\&D interfirm collaboration. Res. Policy 23, S. 47-S. 66.
Herfindahl, O., 1982. The Herfindahl Index: Another Measure of Concentration. Business Week, May 17.

Hyvarinen, J., Rautiainen, A.M., 2007. Measuring additionally and systemic impacts of public research and development funding - the case of TEKES, Finland. Res. Eval. 16, 205-215.

Kleinknecht, A., Reijnen, J.O.N., 1991. More evidence on the undercounting of small firm R\&D. Res. Policy 20 (6), 579-587.

Lane, D.A., Maxfield, R., 1997. Foresight Complexity and Strategy. In: Arthur, W.B., Durlauf, S., Lane, D.A. (Eds.), The Economy as an Evolving Complex System II. Addison Wesley, Redwood City, CA.

Malerba, F., 2009. Increase Learning, Breaks Knowledge Lock-ins and Foster Dynamic Complementarities: Evolutionary and System Perspectives on Technology Policy in Industrial Dynamics. In: Foray, D. (Ed.), The New Economics of Technology Policy. Edward Elgar Publishing.

Maurer, I., Ebers, M., 2006. Dynamics of social capital and their performance implications: lessons from biotechnology start-ups. Adm. Sci. Q. 51 (2), 262-292.

Muscio, A., 2007. The impact of absorptive capacity on SMEs' collaboration. Econ. Innov. N. Technol. 16 (8), 653-668.

Musiolik, J., Markard, J., Hekkert, M., 2012. Networks and network resources in technological innovation systems: towards a conceptual framework for system building. Technol. Forecast. Soc. Chang. 79 (6), 1032-1048.

Narula, R., 2004. R\&D collaboration by SMEs: new opportunities and limitations in the face of globalisation. Technovation 24 (2), 153-161.

Nooteboom, B., 2004. Inter-firm Collaboration, Learning and Networks. An Integrated Approach. Routledge, London and New York.

Powell, W.W., Koput, K.W., Smith-Doerr, L., 1996. Interorganizational collaboration and the locus of innovation: networks of learning in biotechnology. Adm. Sci. Q. 41 (1), $116-145$.

Russo, M., Rossi, F., 2009. Cooperation Partnerships and Innovation. A Complex System Perspective to the Design, Management and Evaluation of an EU Regional Innovation Policy Programme, Evaluation 15(1), pp. 75-100.

Sakakibara, M., 1997. Evaluating government-sponsored R\&D consortia in Japan: who benefits and how? Res. Policy 26 (4), 447-473.

Schoonmaker, M.G., Carayannis, E.G., 2010. Assessing the value of regional innovation networks. J. Knowl. Econ. 1 (1), 48-66.

Schwartz, M., Peglow, F., Fritsch, M., Günther, J., 2010. What Determines the Innovative Success of Subsidized Collaborative R\&D Projects? Project-level Evidence from Germany (No. 2010, 7. IWH-Diskussionspapiere.

Tindemans, P., 2009. Post-war research, education and innovation policy-making in Europe. In: Delanghe, H., Muldur, U., Soete, L. (Eds.), European Science and Technology Policy: Towards Integration or Fragmentation?Edward Elgar, Cheltenham.

Von Hippel, E., 1988. Sources of Innovation. Oxford University Press, Oxford.

Federica Rossi is a Lecturer at Birkbeck, University of London, UK. She has worked as a consultant for the OECD, the UK's Strategic Advisory Board for Intellectual Property, the EC/Eurostat and regional and local development agencies. She has also worked on several national and international research projects. Her research interests focus on the economics and management of intellectual property rights, innovation activities of firms and networks of firms, the economics and governance of the higher education sector, science and technology policy. She has authored numerous articles in peer-reviewed journals and books.

Annalisa Caloffi is an Assistant Professor at the Department of Economics and Business University of Padua, Italy. Her main research interests include industrial and innovation policies, innovation networks and R\&D consortia. She has been involved in a number of international research projects on innovation policies, including EU Research Framework projects, as well as in several projects funded by national and regional agencies. Her works have been presented in several conferences worldwide and published in peer-reviewed journals, books and other national and international outlets.

Margherita Russo is a Professor in Economic Policy, University of Modena and Reggio Emilia, Italy. Her main research topics (both theory and empirical research) are dynamics of innovation (innovation as a social process, the role of relationships between firms in fueling innovation processes, innovation policies, the effects of innovation on the organisation of work and skills); structure and change in local production systems (emergence of networks of competences in local development processes, local development policies; competitiveness of local production systems, environmental and social sustainability of local development). In the last decade she has been involved in several international research projects and EU projects on theory, models and analysis of innovative processes. 